\title{
Intraseasonal variability of winter precipitation over Central Asia and the Western Tibetan plateau from 1979 to 2013 and its relationship with the North Atlantic Oscillation
}

Article

Accepted Version

Creative Commons: Attribution-Noncommercial-No Derivative Works 4.0

Liu, H., Liu, X. and Dong, B. (2017) Intraseasonal variability of winter precipitation over Central Asia and the Western Tibetan plateau from 1979 to 2013 and its relationship with the North Atlantic Oscillation. Dynamics of Atmospheres and Oceans, 79. pp. 31-42. ISSN 0377-0265 doi:

https://doi.org/10.1016/j.dynatmoce.2017.07.001 Available at https://centaur.reading.ac.uk/73198/

It is advisable to refer to the publisher's version if you intend to cite from the work. See Guidance on citing.

Published version at: https://doi.org/10.1016/j.dynatmoce.2017.07.001

To link to this article DOI: http://dx.doi.org/10.1016/j.dynatmoce.2017.07.001

Publisher: Elsevier

All outputs in CentAUR are protected by Intellectual Property Rights law, including copyright law. Copyright and IPR is retained by the creators or other copyright holders. Terms and conditions for use of this material are defined in the End User Agreement. 


\section{www.reading.ac.uk/centaur}

\section{CentAUR}

Central Archive at the University of Reading

Reading's research outputs online 
Intraseasonal Variability of Winter Precipitation over Central Asia and the Western Tibetan Plateau from 1979 to 2013 and its Relationship with the North Atlantic Oscillation

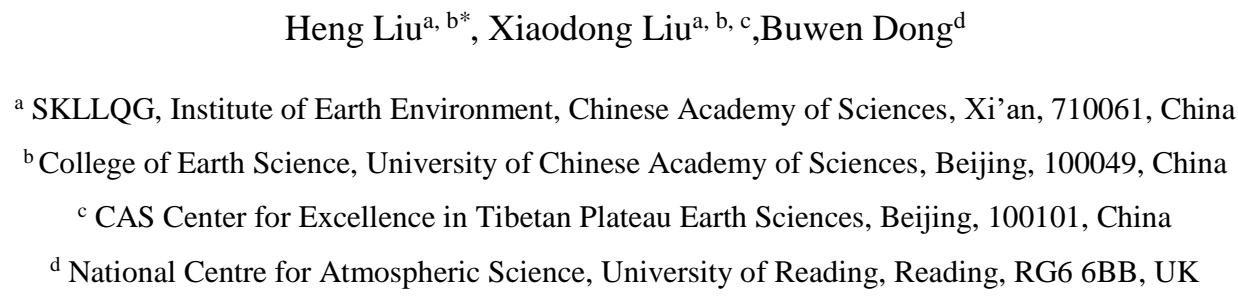

* Corresponding author. E-mail address: liuheng@ieecas.cn 
of the $500 \mathrm{hPa}$ geopotential height anomalies over the southern and northern North Atlantic 10 days earlier (at 95\% significance level), that bear a similarity to the North Atlantic Oscillation (NAO). The composite analysis revealed that the NAO impacts the downstream regions including CAWTP by controlling south-north two branches of the middle latitude westerly circulation around the Eurasian border. During the positive phases of the NAO, the northern branch of the westerly circulation goes around the northwest Tibetan Plateau, whereas the southern branch encounters the southwest Tibetan Plateau, which leads to a reduced precipitation over the northern Pamir Plateau and an increased precipitation over the Karakoram Himalaya, and vice versa.

KEY WORDS: Topographic precipitation; North Atlantic Oscillation; Westerly circulation; Statistical analysis; Intraseasonal variability.

\section{Introduction}

The geographical region covered by Central Asia and the western Tibetan Plateau (CAWTP, $30-45^{\circ} \mathrm{N}, 60-85^{\circ} \mathrm{E}$ ) has complex terrains and a unique climate. The Turan Depression is located in the northwest, whereas the high mountains and plateaus (e.g. the Iran Plateau, the Hindu Kush, the Karakoram Himalaya, the Pamir Plateau and the Tian Shan mountains) are located from the southwest to the northeast (Fig. 1). The CAWTP region has an arid to semiarid climate with an annual precipitation less than $400 \mathrm{~mm}$, except for a few of the high mountain areas. Because of the scarcity of water resources, there is a high risk that global climate change will threaten both the natural environment and the human population in this region (Ragab \& 
Prudhomme 2002, WB et al. 2009).

Despite the complex topography and lack of meteorological stations, satellite remote sensing data have been used to determine the spatiotemporal distribution of precipitation over Central Asia (Guo et al. 2015) and the western Tibetan Plateau (Pohl et al. 2015). Highresolution regional climate models have also been used to determine the patterns of precipitation over CAWTP (Small et al. 1999, Schiemann et al. 2008, Ozturk et al. 2012, Maussion et al. 2014).

Previous studies have reported the spatiotemporal distribution and regional differences in precipitation over CAWTP and have found that the major weather system controlling the winter precipitation over CAWTP is the westerly circulation (Schiemann et al. 2009, Yin et al. 2014). In winter, the westerly circulation transports moisture to Central Asia (Bothe et al. 2012), southwest Asia (Malik et al. 2015) and the western Tibetan Plateau (Curio et al. 2015). The westerly circulation is disturbed by the high mountains in this region and causes heavy precipitation and storms over the Pamir Plateau, the Hindu Kush, the Karakoram Himalaya and the western Himalaya (Lang \& Barros 2004, Cannon et al. 2015a, b). Yin et al. (2014) compared the differences in precipitation climatology between the arid area of Central Asia and the East Asia monsoon region and showed that winter is the rainy season in Central Asia, whereas the rainy season occurs in summer for East Asia. They further showed that the control atmospheric circulation over the western area changes between winter and summer. In winter it is dominated by westerly upper-air flows, bringing moisture from the upstream to the region while in summer it is dominated by northeasterly winds from the Asian interior, resulting in a 
dry condition. The westerly circulation is not only the major weather system controlling the winter mean precipitation over CAWTP, but also precipitation interannual variability and trend in the region (Chen et al. 2011, Yin et al. 2014, Cannon et al. 2015a).

There have been many reports that large-scale atmospheric teleconnections regulate the mid-latitude westerly circulation variability which in turn may influence interannual precipitation variation over CAWTP (e.g. Aizen et al. 2001, Syed et al. 2006, Mariotti 2007, Filippi et al. 2014, Yin et al. 2014, Cannon et al. 2015a, b, Hoell et al. 2015). Although some evidence has been found that at interannual time scale the El Niño-Southern Oscillation may be related to the precipitation variation in the cold season over Central and Western Asia (Mariotti 2007, Hoell et al. 2015), other research has shown a close relationship between the winter interannual precipitation variation over CAWTP and the North Atlantic Oscillation (NAO) (Aizen et al. 2001, Syed et al. 2006, 2010, Yadav et al. 2009, Filippi et al. 2014, Yao and Chen 2015). Aizen et al. (2001) analyzed the relationship between mid-latitude precipitation in Asia and the large-scale circulation of the atmosphere using data from hydro-meteorological stations. Their results showed more precipitation over the Pamir and Tian Shan mountains during the positive phases of the NAO. Syed et al. (2006) found a positive precipitation anomaly over northwestern Asia that is well matched with the positive phase of the NAO. Syed et al. (2010) presented a regional climate modeling study on both NAO and ENSO and discussed the influence of westerly disturbances. Filippi et al. (2014) verified that winter interannual precipitation variation over the Hindu Kush-Karakoram Himalaya region is affected by the NAO. During the positive phases of the NAO, the Middle East, which is 
upstream of CAWTP, experiences stronger westerly winds and evaporation, which leads to an enhanced moisture transport and therefore enhanced precipitation over the Hindu Kush. Yao and Chen (2015) found a significant negative correlation between the yearly precipitation on mountains of the Syr Darya River Basin and NAO index from 1891 to 2011 but it turned out non-significant on plains.

Previous studies have mainly considered the interannual variation in winter precipitation over a specific area and its connection with the NAO and other large-scale circulations (e.g. Aizen et al. 2001, Syed et al. 2006, Mariotti 2007, Filippi et al. 2014, Yin et al. 2014, Cannon et al. 2015a, Hoell et al. 2015). However, little attention has been paid to the spatiotemporal distribution of precipitation variability over CAWTP at the intraseasonal time scale. Therefore it is important to investigate the spatial and temporal distribution of winter precipitation variation over CAWTP on this time scale, to analyze its connection with regional and largescale circulations and to elucidate physical processes involved by using daily precipitation data and other meteorological parameters.

\section{Data and methods}

Daily precipitation data from the Climate Prediction Center (Chen et al. 2008) and daily meteorological variables of ERA-Interim from the European Centre for Medium-Range Weather Forecasts (Dee et al. 2011) were used in this study. Sapna Rana (2017) have already used the CPC Unified Rain gauge data and compared it with 9 other precipitation products over the central southwest Asia. Their results show that the CPC data can reasonably reflect 
the spatial-temporal distribution of winter precipitation over CAWTP despite some systematic differences in the time means The used ERA-Interim variables include the daily 700 and 500 hPa geopotential height, meridional and zonal winds, the total column of water vapor (TCWV) and the mean sea level pressure. The horizontal resolution of all the data is $0.5^{\circ}$ longitude $\times$ $0.5^{\circ}$ latitude. In consideration of the higher accuracy of the reanalysis data obtained over high mountain areas after 1979, when satellite data were first applied (Cannon et al. 2015b), we chose all winters (December-March), consistent with other studies analyzing the relationships between teleconnection patterns and precipitation in this area (Syed et al. 2006, 2010, Yadav et al. 2009, Filippi et al. 2014) from 1979 to 2013, a total of 4244 days, as the study period. The daily average data were obtained from four records with a six-hour interval for each day. The encounter of westerly wind with high mountains of Tibetan Plateau happened around $700 \mathrm{hPa}$, which is closely connected with topographic precipitation, and therefore $700 \mathrm{hPa}$ wind is used to indicate low tropospheric circulation. The $500 \mathrm{hPa}$ geopotential height anomaly can indicate the teleconnections.

To determine the characteristics of the winter intraseasonal precipitation and circulation variability in CAWTP, the climatological seasonal cycle from December to the next March in the daily data was removed before the analysis. We averaged the data of the same date of all the years (1979-2013) and then calculated the 21 day moving mean as the climate mean state. Thus, the daily values with climatological seasonal cycle removed were obtained by subtracting the climate mean state from the actual data according to the following formula:

$$
Z_{n}^{*}=Z_{n}-\left(\sum_{i=-10,10}\left(\sum_{j=1,35} Z_{k+(i-1) \times 365+j}\right) / 35\right) / 21
$$


where $n$ is the number of days from December 1,$1979 ; k$ is the number of days from 129

December 1 of a specific year; $i$ is the number of years from 1979; $j$ is the day from 10 days 130 before to 10 days after a specific day; and $Z_{n}{ }^{*}$ is the value after removing the climatological seasonal cycle.

CAWTP to find the spatial patterns as well as their time variation (Bjornsson and Venegas 134

1997). Figure 1 shows the study area with 1581 grid boxes and 4244 day time series at each grid box, which is the basis for the EOF analysis.

Singular value decomposition (SVD) analysis (Wallace et al. 1992) was applied to show the spatiotemporal relationship between the winter daily precipitation and the regional defined as the standardized difference in mean sea level pressure between the southern 
(Hurrell 1996). After calculating the daily index for every winter from 1979 to 2013, the central day of a positive (negative) NAO phase event was defined as the day with the relative maximum (minimum) value of the NAO index in continuous five days and being greater (less) than $1.5(-1.5)$ at the same time. In this way, a total of 85 positive NAO phase cases and 82 negative phase cases were selected for the composites. Here we did composite analysis based on cases with strong NAO anomalies in order to see teleconnections between two regions and significant NAO related remote climatic anomalies over CAWTP. To trace westerly wind disturbance (WWD) tracks, a wave-tracking approach was applied as documented in Cannon (2015b) who defined the centers of the disturbances by standardized $500 \mathrm{hPa}$ geopotential height anomaly and a set of spatial threshold and temporal correlation to identify the tracks. Here we used the $500 \mathrm{hPa}$ geopotential height anomaly of 1 standard deviation and the spatial extent of 5 degrees as a set of thresholds to identify the location of centers to count the WWDs. Then the WWD frequency in every grid was calculated.

\section{Spatial and temporal distribution of winter precipitation over CAWTP and its connection}

\section{with the contemporaneous regional circulation}

\subsection{Winter precipitation climatology over CAWTP}

The climate of Central Asia is controlled on an annual basis by westerly winds containing little moisture, and it is classified as a typical arid to semiarid region. The rainy season usually occurs in winter (from December to March) (Yin et al. 2014) and most of the moisture transported by the strong westerly winds is intercepted to condense by the high mountains 
of the region during this period (Syed et al. 2006). Figure 2a shows the spatial distribution of the winter mean climatological precipitation over Asia from 1979 to 2013 . There is more

3.2 Intraseasonal variability in winter daily precipitation and circulation over CAWTP It is possible that the strength and position of westerly circulation determine the forced 
upward motion, frequency of WWDs and the distribution of precipitation on the intraseasonal

time scale. The winter daily precipitation was decomposed by EOF analysis after the climatological seasonal cycle was removed and the first two modes are shown in Fig. 3a and 3b. The first mode shows the same sign allover CAWTP with explained variance of $24.4 \%$ and the second mode shows a seesaw pattern between northern Pamir Plateau and the Karakoram Himalaya with explained variance of $15.6 \%$. These EOF modes suggest the existence of the intraseasonal variability of winter precipitation over CAWTP. Then we composited the $500 \mathrm{hPa}$ zonal wind (U component) during the dominant periods according to the time series of the first mode and the second mode as Fig. $3 c$ and Fig. $3 d$, which indicated close connection between regional circulation and precipitation. Therefore, the relationship between the regional circulation and precipitation in the study area is explored in the following.

The seasonal cycle removed daily precipitation and $700 \mathrm{hPa}$ moisture flux fields for 35 winters during 1979-2013 were used for the SVD analysis to determine the simultaneous relationship between the precipitation and circulation variability over CAWTP. The first SVD mode shows a dipole pattern of precipitation variability with a positive anomaly over the Karakoram Himalaya (center located at $33^{\circ} \mathrm{N}, 78^{\circ} \mathrm{E}$, Fig.4a) and a negative anomaly over the northern Pamir Plateau (center located at $40^{\circ} \mathrm{N}, 68^{\circ} \mathrm{E}$ ), bearing a very similar structure as shown for the second mode of EOF analysis (Fig. 3b). Accompanied with this pattern of precipitation variability is a southerly wind anomaly over the Karakoram Himalaya and a northwesterly wind anomaly (southwesterly wind weakened) over the northern Pamir 
Plateau(not shown) and anomalous lower tropospheric moisture transport (Fig. 4b). This pattern of precipitation anomaly is closely related to the forced lifting of the westerly airstream on the windward side of the mountains. The explained variance reaches $55.12 \%$ and the correlation coefficient between the time coefficients of two fields is 0.65 for the first SVD mode, suggesting the importance of orographic forcing in modulating the regional precipitation at the intraseasonal time scale.

We also did the SVD analysis with the seasonal cycle removed daily precipitation and 500 hPa geopotential height fields over CAWTP. The explained variance and correlation coefficient corresponding for the first SVD mode are $60.5 \%$ and 0.64 , respectively (Fig. $4 \mathrm{c}$ and d). Figs. 4c and $4 \mathrm{~d}$ illustrate that a negative center over the southeast of CAWTP in the field of $500 \mathrm{hPa}$ geopotential height anomaly is associated with a precipitation anomaly pattern with the wetter southeast and the drier northwest. Hence, the distribution of winter precipitation anomaly in the study area at the intraseasonal time scale is the result of topography-affected regional atmospheric circulation variability. In the following, a lead-lag linear regression was used to further reveal the relationship between the regional and large-scale circulation variations and the regional precipitation change.

\section{Correlation of $500 \mathrm{hPa}$ geopotential height over CAWTP with the preceding atmospheric} circulation over the North Atlantic Ocean and Eurasia

The preceding atmospheric circulation over the Atlantic Ocean and Eurasian region may influence the regional circulation over CAWTP, leading to the regional precipitation anomaly 
via teleconnection. The time series of the $500 \mathrm{hPa}$ geopotential height analyzed by SVD was normalized and then the normalized time series with an absolute value greater than 1.5 and higher than the neighboring 4 other days was chosen for further analysis (a total of 200 time series mixed with both positive and negative values). A linear regression was applied between the chosen 200 time series and the antecedent $500 \mathrm{hPa}$ geopotential height field over the Atlantic Ocean-Eurasian region from lead 16 days to the lag 3 day of the chosen days respectively and results are shown in figure 5 . There is a positive geopotential height anomaly over the Azores (center located at $30^{\circ} \mathrm{W}$ and $40^{\circ} \mathrm{N}$ ) and a negative anomaly over Iceland (center located at $10^{\circ} \mathrm{W}$ and $60^{\circ} \mathrm{N}$ ) from day -10 to day -8 (10 to 8 days before the regional circulation phase, the same below) (Fig. 5a, 5b). These patterns of the anomalous circulation show a similarity to the positive phase of the NAO (Hurrell 1996). On day -6 , the original negative geopotential height anomaly over Iceland moves to the east and a significant positive anomaly occurs over the Eurasian border and northern Asia and meanwhile a negative anomaly over CAWTP develops (Fig. 5c). With time advance, the magnitude of the anomaly over the Atlantic Ocean decrease, whereas the strength of the anomalies over the Eurasian border and over CAWTP enhance on day -4 (Fig. $5 d$ ). On day -2 and 0 , significant negative geopotential height anomalies occur over CAWTP (Fig. 5e, 5f), similar to the results of the SVD analysis. It is therefore possible that the regional circulation has been affected by the preceding large-scale circulation variability related to NAO.

The time evolution of the $500 \mathrm{hPa}$ geopotential height anomaly over the North Atlantic was analyzed by lead-lag linear regression and correlation. Areas $A\left(20-40^{\circ} \mathrm{W}, 30-40^{\circ} \mathrm{N}\right), \mathrm{B}$ 
$\left(0-20^{\circ} \mathrm{W}, 54-64^{\circ} \mathrm{N}\right), \mathrm{C}\left(44-64^{\circ} \mathrm{E}, 54-64^{\circ} \mathrm{N}\right)$ and $\mathrm{D}\left(60-80^{\circ} \mathrm{E}, 30-40^{\circ} \mathrm{N}\right)$ in Fig. 5 were chosen

to calculate the average geopotential height anomaly and the correlation coefficient in different lead days. The four domains are recognized in consideration of both covering the centers of $500 \mathrm{hPa}$ geopotential height anomaly and the significant at $95 \%$ level in Fig. 5 . Otherwise, the numbers of the grids of the four domains should be the same so they are comparable. Table 1 lists regression coefficients and correlation coefficients of regionallyaveraged $500 \mathrm{hPa}$ geopotential heights on different lag days for these four areas and the time coefficients of the first mode of $500 \mathrm{hPa}$ geopotential height field over CAWTP in the above SVD analysis. From days -15 to -9 (the negative number means the days before the day for the regional SVD analysis) there is a positive anomaly over area A, a significant increasingly negative anomaly over area B, and no significant anomaly over area C. From days -8 to -4 , the anomaly over area A decreases and the anomaly over area B increases to a maximum value. A significant positive anomaly appears over area $C$ on day -5 and increases rapidly afterwards. From days -3 to 0 there is no significant anomaly over area $A$, the anomaly over area $B$ decreases, and the anomaly over areas $C$ and $D$ increases to maximum values. From days +1 to +3 there is no significant anomaly over area $B$ and the anomaly over areas $C$ and $D$ decreases. Figure 5 and Table 1 show time evolutions of geopotential height anomaly in various regions before the maximum height anomaly over CAWTP and suggest that NAO-like circulation anomaly over the North Atlantic is a precursor for the intraseasonal variation of precipitation over CAWTP. The lead-lag correlation coefficients between NAO index and time series of first SVD mode in these chosen days were calculated and they are given in Table 1. 
These correlation coefficients indicate large correlations when NAO leads the regional geopotential height by about 10 days. CAWTP and geopotential height over the North Atlantic about 10-8 days before by linear regression and correlation, further analysis was required to elucidate the mechanism for the

\section{Influence of the NAO on spatial and temporal distribution of winter precipitation over}

\section{CAWTP}

Based on our definition of NAO events, the $500 \mathrm{hPa}$ geopotential height, the $700 \mathrm{hPa}$ wind flow field were combined to assess the influence of the NAO on the circulation over remote downstream areas. The time evolutions of composited 500hPa geopotential height anomaly and $700 \mathrm{hPa}$ streamlines at different lags for the positive and negative NAO phase cases are illustrated in Fig. 6. In positive NAO phases, the NAO pattern is clearly shown on the 0 day (the peak day of NAO index) with the strong negative $500 \mathrm{hPa}$ geopotential height anomaly over the Iceland and the positive one over the Azores. As time advances, the positive anomaly extends eastward to the Eurasian border. In the following days, NAO pattern is weakening and the east positive anomaly is further extended eastward and is finally separated from the 
positive anomaly over the Azores. The eastward extension of positive anomaly over the

(Fig. 6c). The time evolutions of the $700 \mathrm{hPa}$ wind streamlines associated with geopotential height anomaly evolutions offer another view. Associated with positive NAO at day 0 is a single strong westerly jet over the North Atlantic and two branches of strong westerly wind, whose 
frequency of WWD occur over the Karakoram Himalaya (Fig. 7a). During the negative NAO phases, southwesterly moisture flux anomalies occur over the Central Asia and northern Pamir Plateau, whereas northeasterly moisture flux anomalies accompanied with lower frequency of WWD occur over the Karakoram Himalaya (Fig. 7b). The composites of precipitation anomalies of positive and negative NAO phases, as shown in Fig. 7c and 7d, are well matched with the regional circulation and moisture flux anomalies. There is less precipitation over the north east of Iran, Turkmanistan, Tajikistan and Kyrgyzstan (center at $75^{\circ} \mathrm{E}, 34^{\circ} \mathrm{N}$ ) and more precipitation over the Karakoram Himalaya (center at $\sim 70^{\circ} \mathrm{E}, 42^{\circ} \mathrm{N}$ ) during positive NAO phases and vice versa. For the south part, the WWD seems to be more important while the moisture flux takes control of the north part. Compared with the daily average winter precipitation (Fig. 2a), the precipitation anomaly at the intraseasonal time scale reaches $10 \%$ of the climatological mean. The precipitation composites during the different NAO phases are similar to the results of the SVD analyses. The two analyses both demonstrate the teleconnection between the NAO over the North Atlantic and the regional circulation and precipitation variability over CAWTP.

\section{Discussion and conclusions}

The climate is characterized by dominant westerly circulation and scarce precipitation over CAWTP. The lowlands of this area are almost rainless due to the lack of moisture and upward motion. By contrast, heavy rains occur on the high mountain areas as a result of the uplifting of the westerly winds by the high topography. 
There have been much published research on precipitation and its interannual variability over the Karakoram Himalaya (Syed et al. 2006, 2010, Filippi et al. 2014, Cannon et al. 2015a, b). For example, Cannon et al. (2015a, b) stressed the importance of the westerly disturbance. Less research has focused on precipitation over the northern Pamir Plateau and mainly

focuses on interannual variations (e.g., Chen et al. 2011). Filippi et al. (2014) and Syed et al. (2006) found that the interannual variation in precipitation is connected to the NAO, but they did not discuss the intraseasonal precipitation variations and the contemporaneous opposite variations over the northern Pamir Plateau and over the Karakoram Himalaya.

This study focused on the intraseasonal variation in winter daily precipitation over CAWTP. The EOF, SVD, lead-lag linear regression and composite analyses showed that a seesaw pattern of winter intraseasonal precipitation anomaly between the Karakoram Himalaya and the northern Pamir Plateau is connected with the intraseasonal oscillation of the NAO. The main physical processes for the seasaw pattern of precipitation variability are the trough-ridge phase of the two westerly jets rather than the westerly strength at the intraseasonal scale. Multi-method analyses gave similar results, confirming that the NAO is able to influence the intraseasonal precipitation variability in winter over CAWTP.

The seesaw pattern of winter intraseasonal precipitation anomaly was found between the southeastern CAWTP (centered in the Karakoram Himalaya) and the northwestern CAWTP (centered in the northern Pamir Plateau) by the SVD analysis and this pattern of precipitation was closely connected to the regional $700 \mathrm{hPa}$ circulation. When there was a northeasterly moisture flux anomaly (southwesterly moisture flux weakened) over the northwestern CAWTP 
and a southwesterly moisture flux anomaly (southwesterly moisture flux strengthened) over the southwestern CAWTP at $700 \mathrm{hPa}$, a negative precipitation anomaly occurred over the

The mechanism for the seesaw precipitation anomaly over CAWTP may be related to the NAO-like circulation at the intraseasonal time scale. The results of both the regression and composite analyses showed that the seesaw precipitation pattern was closely connected with the precursor NAO-like circulation anomalies over the North Atlantic. During the positive NAO phases, the southern branch of the $700 \mathrm{hPa}$ westerly winds formed a ridge over the North Atlantic and combined with the northern branch which formed a trough. The two branches separated around Eurasian border. The southern branch then formed a trough over the Middle East, which increased the transport of moisture and the strength of the westerly winds over the Karakoram Himalaya. By contrast, the northern branch formed a ridge and went around the northwestern Tibetan Plateau, which decreased southwesterly winds, the southwesterly moisture transport, and therefore precipitation over the Central Asia and northern Pamir Plateau. The large scale wind stream pattern can modify the regional circulation. Meanwhile during positive NAO, more WWD occurred over the Karakoram Himalaya since south branch of westerly encounters the Himalaya, which finally increased the precipitation over Karakoram Himalaya. This pattern was reversed during the negative NAO phases. The main physical processes involved and discussed above for the influence of the NAO on the winter 
precipitation variability at the intraseasonal time scale over CAWTP are illustrated in

schematic diagrams of Fig. 8.

382

Acknowledgments. This work was jointly supported by the National Key Research and

Development Program of China (2016YFA0601904) and the National Natural Science

\section{LITERATURE CITED}

Aizen E M, Aizen V B, Melack J M and others (2001) Precipitation and atmospheric circulation patterns at mid-latitudes of Asia. International Journal of Climatology 21: 535-556

Bjornsson H, Venegas S A (1997) A manual for EOF and SVD analyses of climatic data. CCGCR Report97: 112-134

Bothe O, Fraedrich K, Zhu X (2012) Precipitation climate of Central Asia and the large-scale atmospheric circulation. Theoretical and Applied Climatology108: 345-354

Cannon F, Carvalho L M V, Jones C and others (2015a) Multi-annual variations in winter westerly disturbance activity affecting the Himalaya. Climate Dynamics 44: 441-455

Cannon F, Carvalho L M V, Jones C and others (2015b) Winter westerly disturbance dynamics 
and precipitation in the western Himalaya and Karakoram: a wave-tracking approach.

Chen FH, Huang W, Jin LY, Chen J and others (2011) Spatiotemporal precipitation variations in the arid Central Asia in the context of global warming.Science China Earth Sciences 54: $1812-1821$

Chen M, Shi W, Xie P and others (2008) Assessing objective techniques for gauge-based analyses of global daily precipitation. Journal of Geophysical Research: Atmospheres113: D04110, doi:10.1029/2007JD009132

Curio J, Maussion F, Scherer D (2015) A 12-year high-resolution climatology of atmospheric water transport over the Tibetan Plateau. Earth System Dynamics 6: 109-124

Dee D P, Uppala S M, Simmons A J and others (2011) The ERA-Interim reanalysis: Configuration and performance of the data assimilation system. Quarterly Journal of the Royal Meteorological Society 137: 553-597

Filippi L, Palazzi E, von Hardenberg J and others (2014) Multidecadal variations in the relationship between the NAO and winter precipitation in the Hindu Kush-Karakoram. Journal of Climate27: 7890-7902

Guo H, Chen S, Bao A and others (2015) Inter-comparison of high-resolution satellite precipitation products over Central Asia. Remote Sensing 7: 7181-7211

Hoell A, Shukla S, Barlow M and others (2015) The forcing of monthly precipitation variability over Southwest Asia during the boreal cold season. Journal of Climate28: 7038-7056

Hurrell, J W (1996) Decadal trends in the North Atlantic Oscillation: regional temperatures 
Lang T J, Barros A P (2004) Winter storms in the central Himalayas. Journal of the Meteorological Society of Japan82: 829-844

Malik K M, Taylor P A, Szeto K (2015) Characteristics of moisture flux convergence in Central Southwest Asia. Theoretical and Applied Climatology 120: 643-659

Ozturk T, Altinsoy H, Türkes M and others (2012) Simulation of temperature and precipitation climatology for the Central Asia CORDEX domain using RegCM 4.0. Climate Research52: 63-76

Pohl E, Gloaguen R, Seiler R (2015) Remote sensing-based assessment of the variability of winter and summer precipitation in the Pamirs and their effects on hydrology and hazards using harmonic time series analysis. Remote Sensing7: 9727-9752

Ragab R, Prudhomme C (2002) Climate change and water resources management in arid and semi-arid regions: prospective and challenges for the 21 st century. Biosystems Engineering 81: 3-34

Rana S, McGregor J, Renwick J (2017) Wintertime precipitation climatology and ENSO sensitivity over central southwest Asia. International Journal of Climatology 37: 1494- 
444 Schiemann R, Lüthi D, Vidale P L and others (2008) The precipitation climate of Central

WB, ISDR, CAREC (2009) Central Asia and Caucasus disaster risk management initiative 
(CAC DRMI), Risk assessment for Central Asia and Caucasus. Desk study review: 1155.http://www.preventionweb.net/files/11641_CentralAsiaCaucasusDRManagementIni t.pdf (accessed 15 Sep 2016)

Yadav R K, Rupa Kumar K, Rajeevan M. (2009) Increasing influence of ENSO and decreasing influence of $\mathrm{AO} / \mathrm{NAO}$ in the recent decades over northwest India winter precipitation. Journal of Geophysical Research: Atmospheres 114(D12)

Yao J, Chen Y. (2015) Trend analysis of temperature and precipitation in the Syr Darya Basin in Central Asia. Theoretical and Applied Climatology 120(3-4): 521-531

472

Yin ZY, Wang HL, Liu XD (2014) A comparative study on precipitation climatology and 474 interannual variability in subtropical East Asia and Central Asia. Journal of Climate27: $7830-7848$ 
477 different lead-lag days for four regions indicated in Fig. 5 with the time coefficients of the

478 first mode of $500 \mathrm{hPa}$ geopotential height field over CAWTP in the SVD analysis mentioned in

479 the text, and the correlation coefficients between NAO index and the time series. A negative

480 lag means that the regionally-averaged height value over the four regions leads the height

481 anomaly over CAWTP in the SVD analysis.

\begin{tabular}{|c|c|c|c|c|c|}
\hline Lag day & Area A & Area B & Area C & Area D & NAOI \\
\hline-16 & 0.13 & -0.14 & -0.06 & $-0.15^{*}$ & $0.19^{* *}$ \\
\hline-15 & $0.16^{*}$ & $-0.22^{* *}$ & -0.01 & $-0.20^{* *}$ & $0.22^{* *}$ \\
\hline-14 & $0.17^{*}$ & $-0.23^{* *}$ & 0.02 & $-0.24^{* *}$ & $0.24^{* *}$ \\
\hline-13 & $0.15^{*}$ & $-0.24^{* *}$ & 0.04 & $-0.26^{* *}$ & $0.24^{* *}$ \\
\hline-12 & 0.14 & $-0.30^{* *}$ & 0.07 & $-0.29^{* *}$ & $0.23^{* *}$ \\
\hline-11 & 0.13 & $-0.33^{* *}$ & 0.11 & $-0.30^{* *}$ & $0.21^{* *}$ \\
\hline-10 & $0.15^{*}$ & $-0.30^{* *}$ & 0.11 & $-0.32^{* *}$ & $0.20^{* *}$ \\
\hline-9 & $0.17^{*}$ & $-0.32^{* *}$ & 0.11 & $-0.35^{* *}$ & $0.20^{* *}$ \\
\hline-8 & 0.14 & $-0.36^{* *}$ & 0.10 & $-0.38^{* *}$ & $0.21^{* *}$ \\
\hline-7 & 0.13 & $-0.44^{* *}$ & 0.11 & $-0.41^{* *}$ & $0.20^{* *}$ \\
\hline-6 & $0.17^{*}$ & $-0.48^{* *}$ & 0.16 & $-0.44^{* *}$ & $0.16^{*}$ \\
\hline-5 & $0.20^{* *}$ & $-0.46^{* *}$ & $0.26^{* *}$ & $-0.47^{* *}$ & 0.12 \\
\hline-4 & $0.17^{*}$ & $-0.46^{* *}$ & $0.39^{* *}$ & $-0.51^{* *}$ & 0.08 \\
\hline-3 & 0.14 & $-0.40^{* *}$ & $0.54^{* *}$ & $-0.59^{* *}$ & 0.05 \\
\hline-2 & 0.14 & $-0.34^{* *}$ & $0.67^{* *}$ & $-0.68^{* *}$ & 0.04 \\
\hline-1 & $0.16^{*}$ & $-0.23^{* *}$ & $0.70^{* *}$ & $-0.75^{* *}$ & 0.04 \\
\hline 0 & $0.15^{*}$ & $-0.17^{*}$ & $0.67^{* *}$ & $-0.67^{* *}$ & 0.00 \\
\hline 1 & 0.12 & $-0.16^{*}$ & $0.59^{* *}$ & $-0.57^{* *}$ & -0.08 \\
\hline 2 & 0.08 & -0.06 & $0.48^{* *}$ & $-0.47^{* *}$ & -0.14 \\
\hline 3 & 0.05 & -0.03 & $0.44^{* *}$ & $-0.39^{* *}$ & -0.14 \\
\hline
\end{tabular}

482

*Significant at the $95 \%$ level

** Significant at the $99 \%$ level 


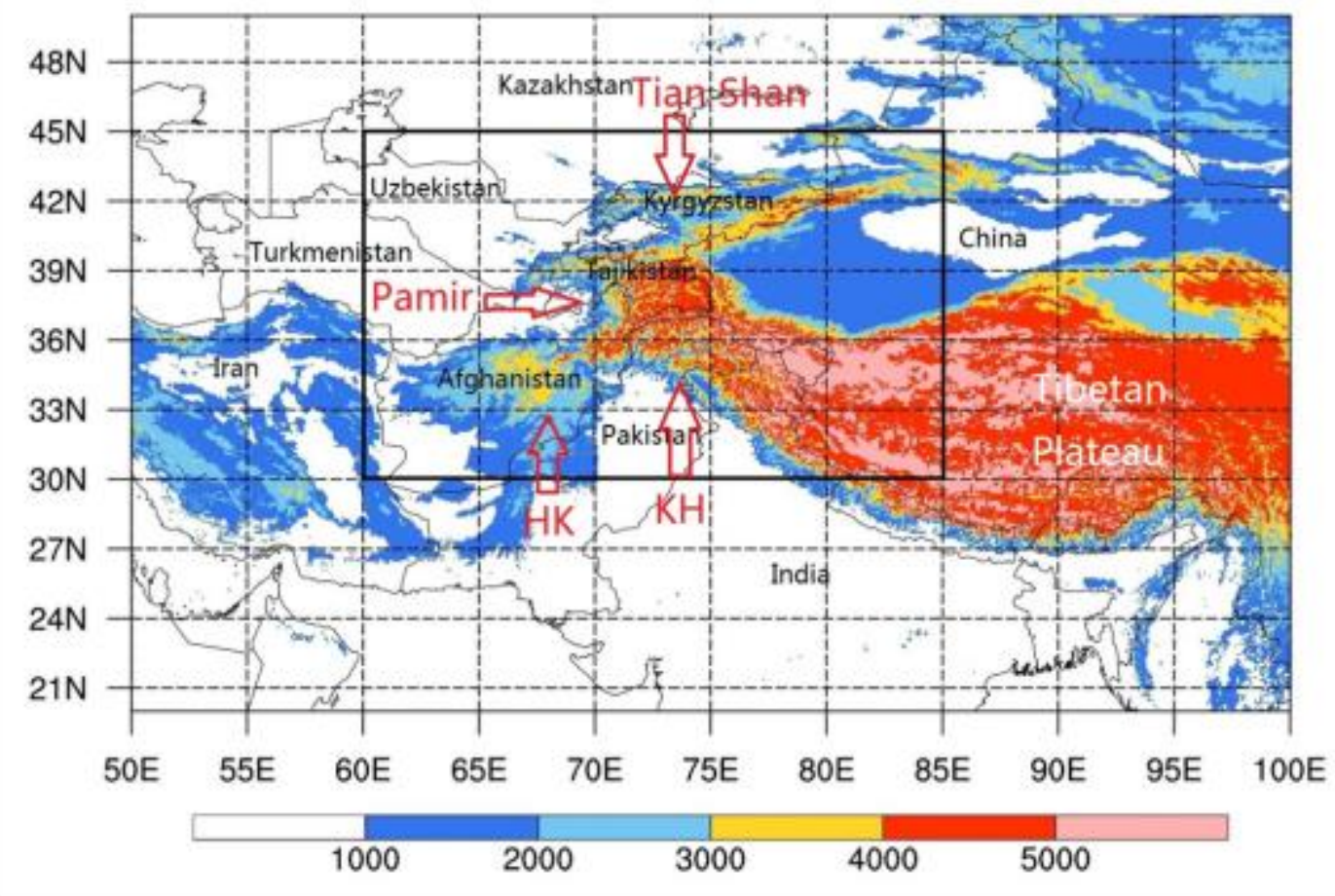

485 Fig. 1. Topography (color shaded areas, in meters) and national boundaries (thin gray lines) of

486 Central Asia, the western Tibetan Plateau (outlined by the black box) and surrounding areas.

$\mathrm{HK}$ and $\mathrm{KH}$ indicate Hindu Kush and Karakoram Himalaya, respectively. 
(a) DJFM-precipitation

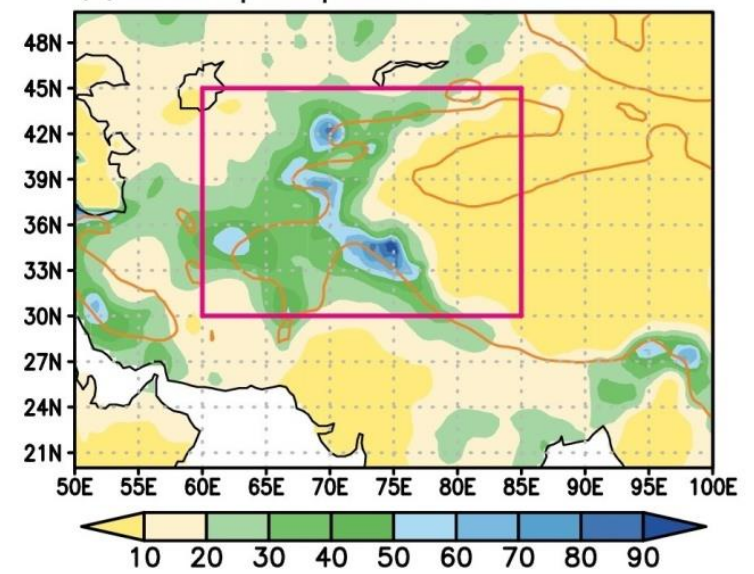

(c) DJFM-950hPa-300hPa moisture flux integral

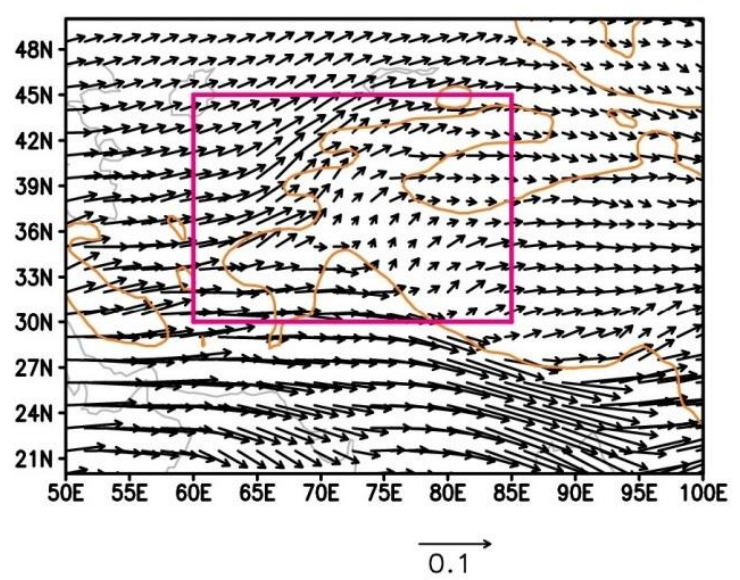

(b) DJFM-percentage of precipitation

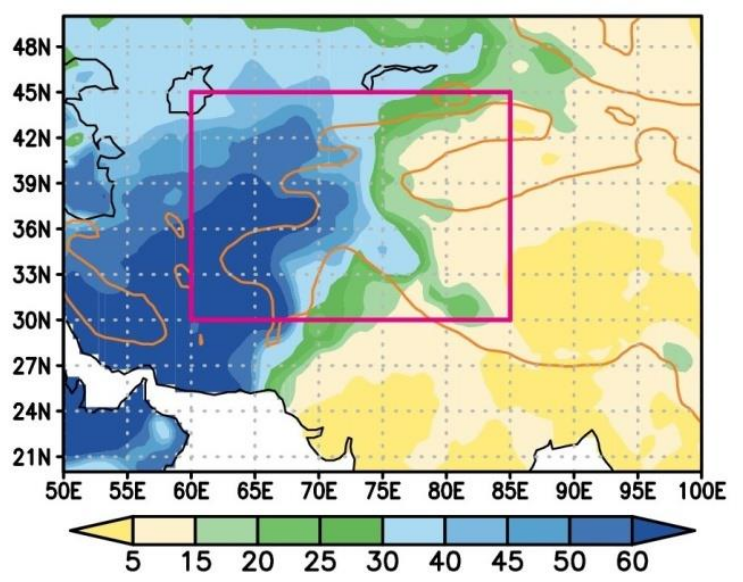

(d) DJFM-WWD frequency

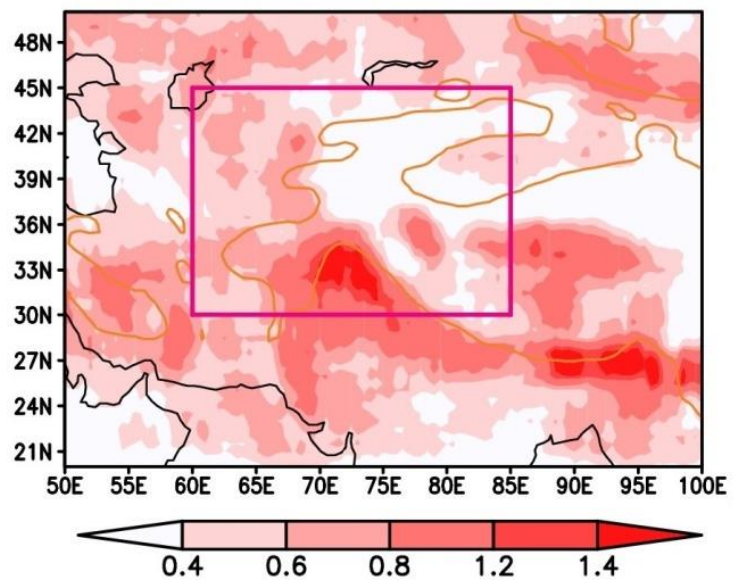

Fig. 2. (a) Average precipitation $\left(0.1 \mathrm{~mm} \mathrm{~d}^{-1}\right)$, (b) percentage of annual precipitation falling in winter (\%), (c) water vapor flux integrated vertically for 950-300 hPa $\left(\mathrm{kg} \mathrm{m}^{-1} \mathrm{~s}^{-1}\right)$ and (d) westerly wind disturbances frequency (percentage per day) in the CAWTP and surrounding areas in winter (December-March) for 1979-2013. The brown lines indicate the topographic contour of $1500 \mathrm{~m}$ and the red boxes represent the CAWTP region. 
(a) First precipitation mode of EOF

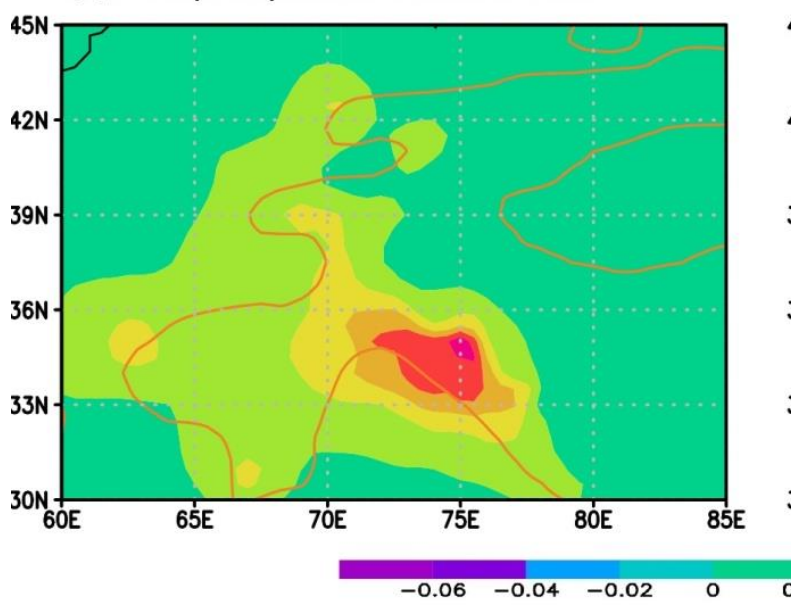

(c) Composited $500 \mathrm{hPa} U$ component of PC1
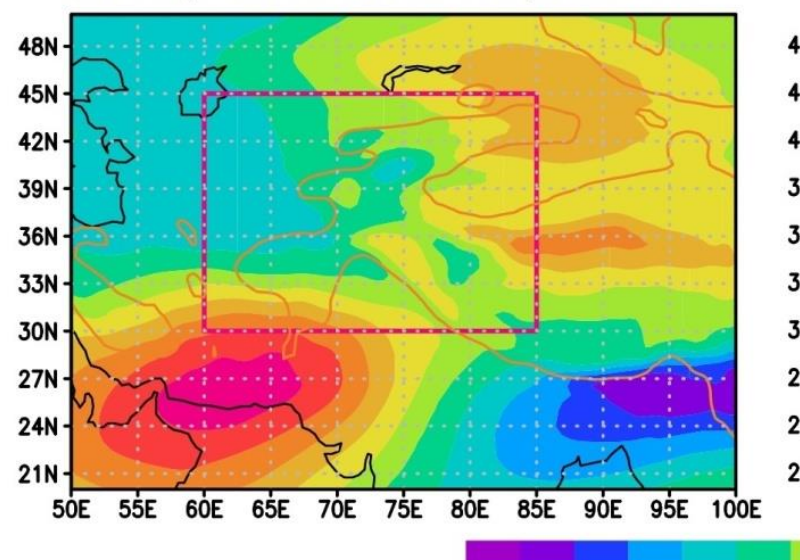

$$
\begin{array}{lllllllllll}
-5 & -4 & -3 & -2 & -1 & 0 & 1 & 2 & 3 & 4 & 5
\end{array}
$$

(b) Second precipitation mode of EOF

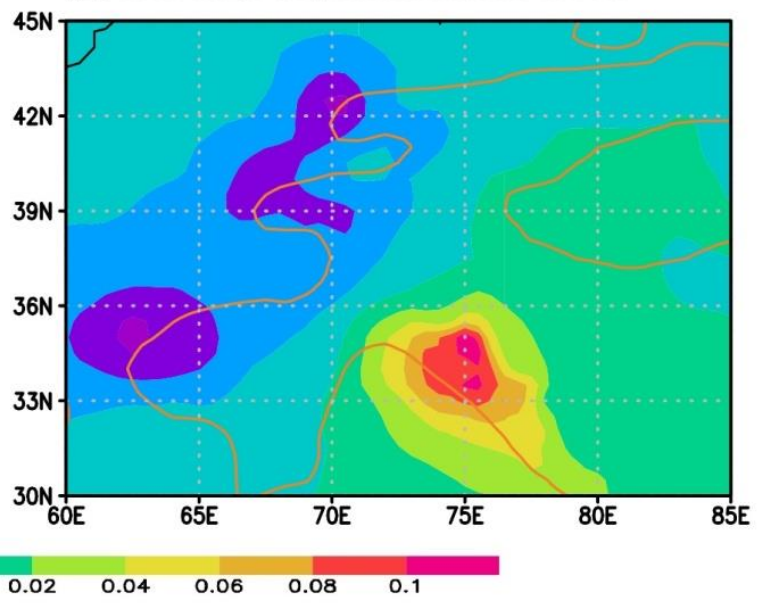

(d) Composited $500 \mathrm{hPa} U$ component of PC2

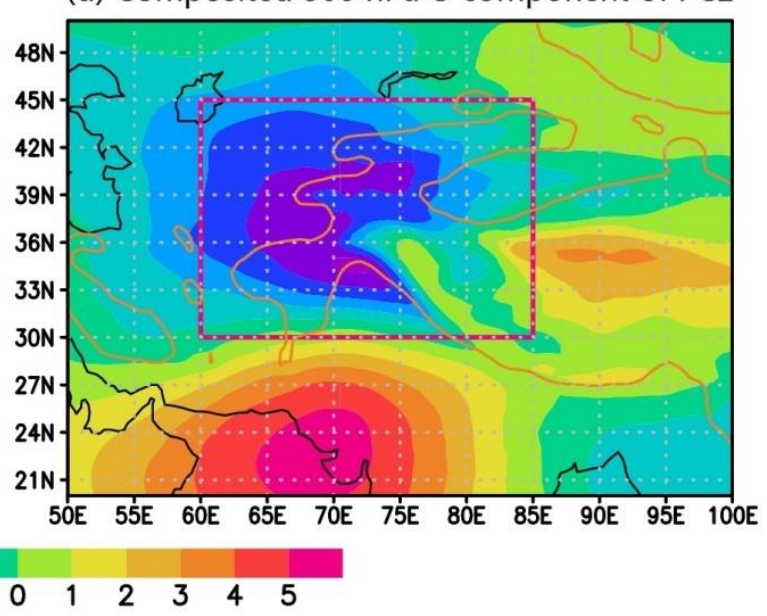

Fig. 3. First mode (a) and second mode (b) of the EOF analysis of daily precipitation field for winters during 1979-2013. The composited $500 \mathrm{hPa}$ zonal wind (U component) of the dominant periods of the First mode (c) and second mode (d). The brown lines represent the topographic contour of $1500 \mathrm{~m}$. 
(a) SVD-precipitation

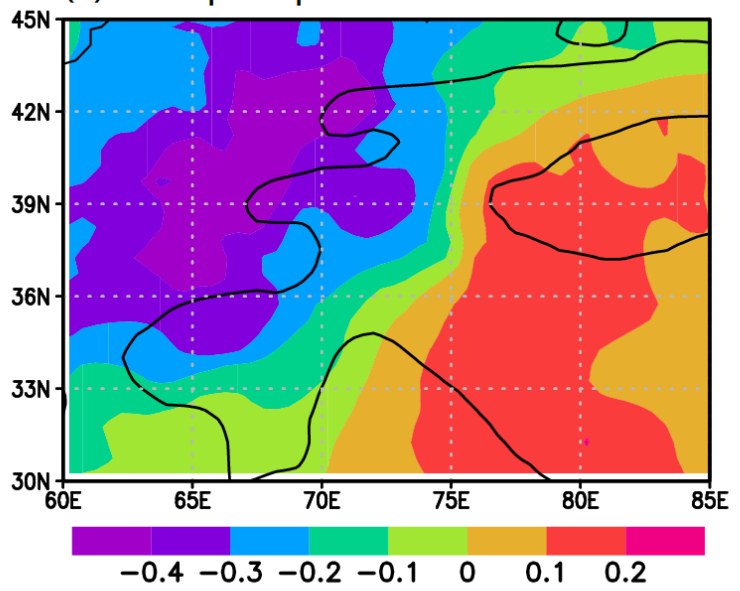

(c) SVD-precipitation

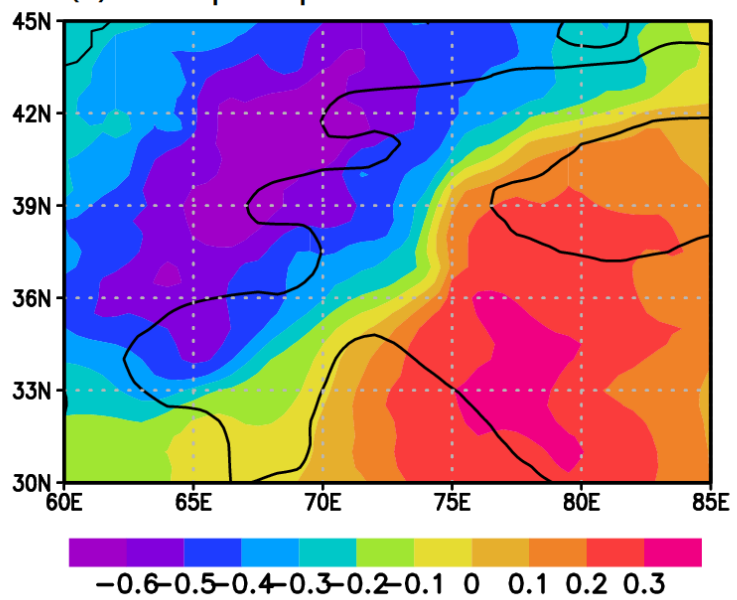

(b) SVD-700hPa moisture flux

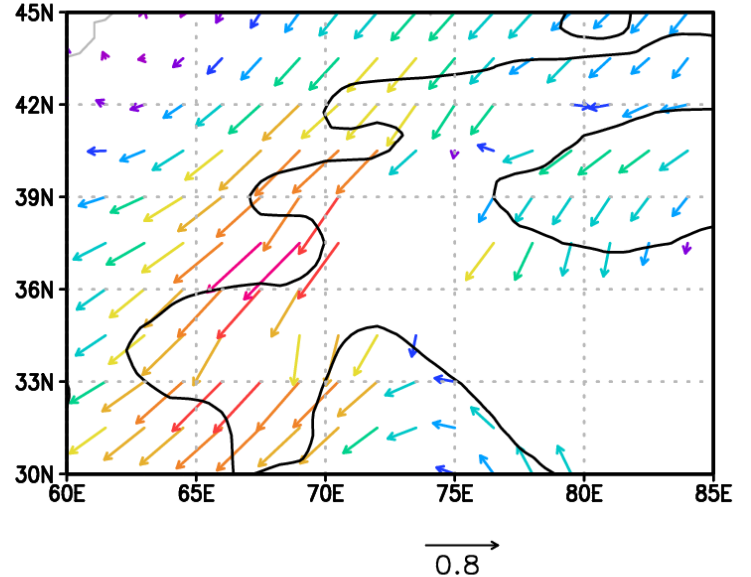

(d) SVD-500hPa geopotential height

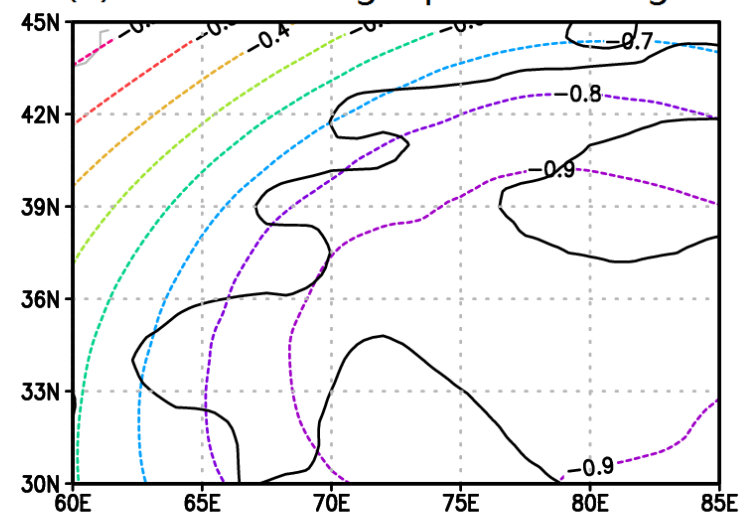

Fig. 4. First mode of the SVD analysis between seasonal cycle removed daily precipitation field

(a) and $700 \mathrm{hPa}$ daily moisture flux field (b) for winters during 1979-2013. Panels (c) and (d) 
(a) -10 day

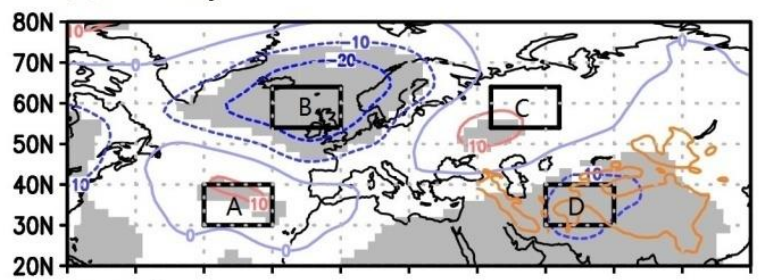

(c) -6 day
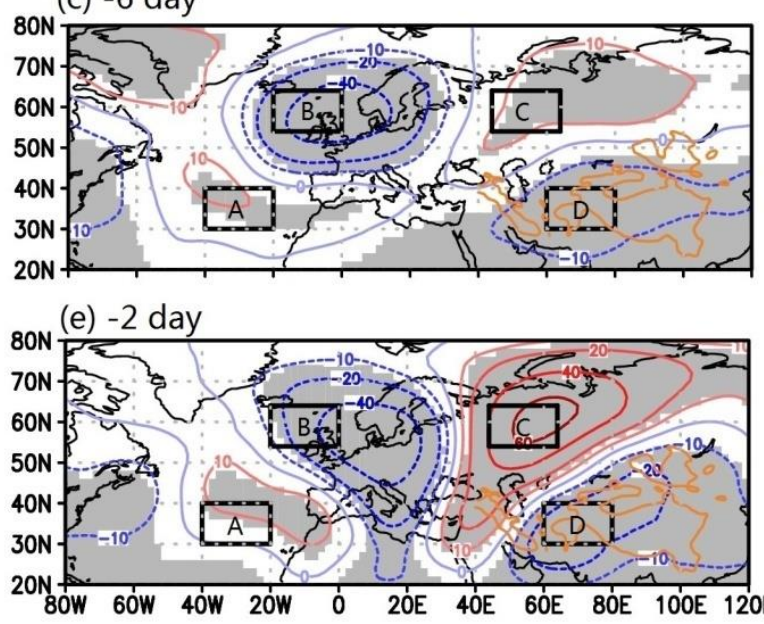

(b) -8 day

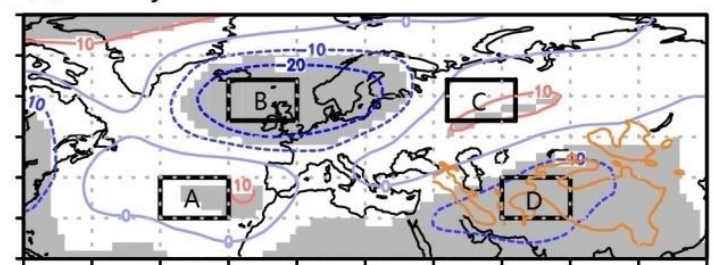

(d) -4 day

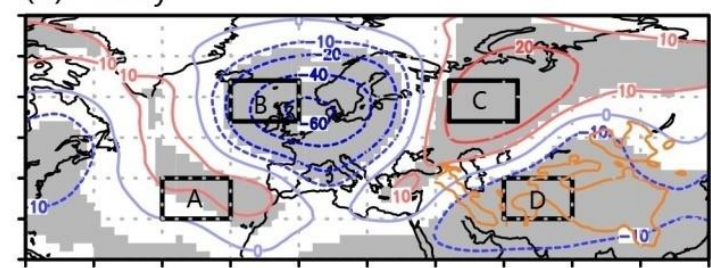

(f) 0 day

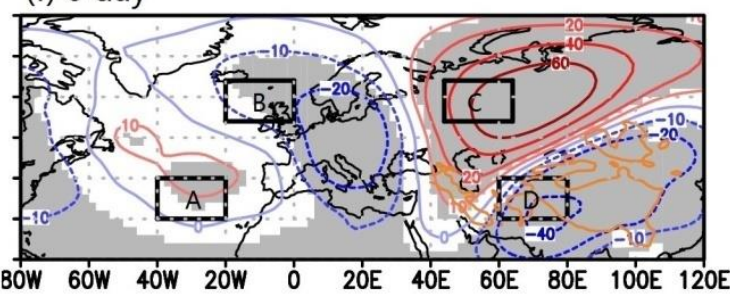

Fig. 5. Regressed 500hPa geopotential height anomaly fields for days (a) -10 , (b) -8 , (c) -6 , (d)

$-4,(e)-2$ and (f) 0 with the chosen 200time coefficients of the first mode of $500 \mathrm{hPa}$

number of days before the day of SVD analysis. The contours represent the regression

coefficients and the gray shading represents the areas that were significant at the $95 \%$ level.

The brown lines represent the $1500 \mathrm{~m}$ topographic height and the black boxes represent the four geopotential height anomaly centers. 
(a) +NAO day 0

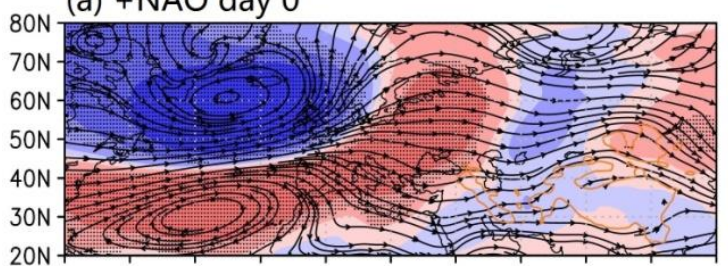

(b) +NAO day 5

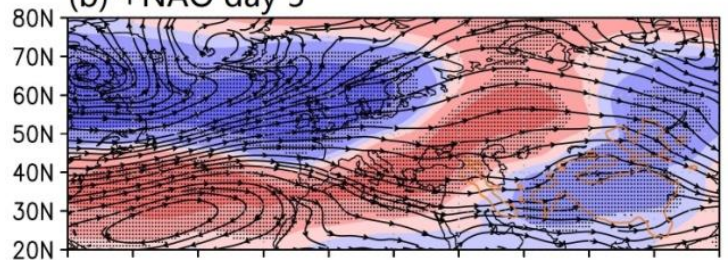

(c) +NAO day 10

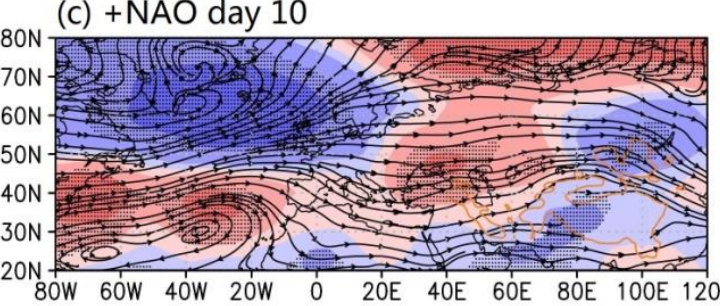

(d) -NAO day 0

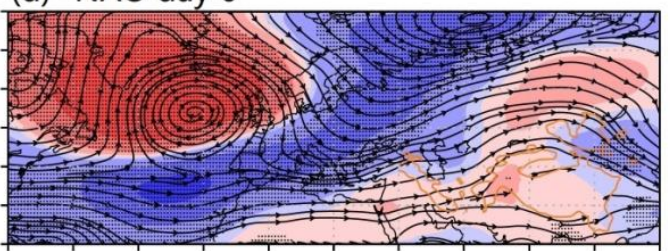

(e) -NAO day 5

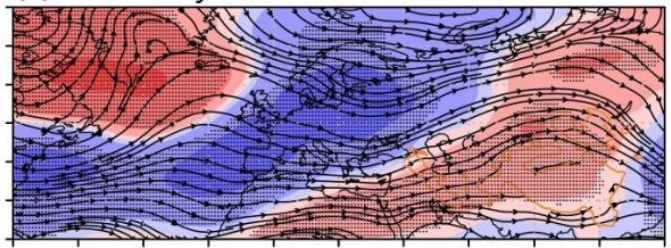

(f) -NAO day 10

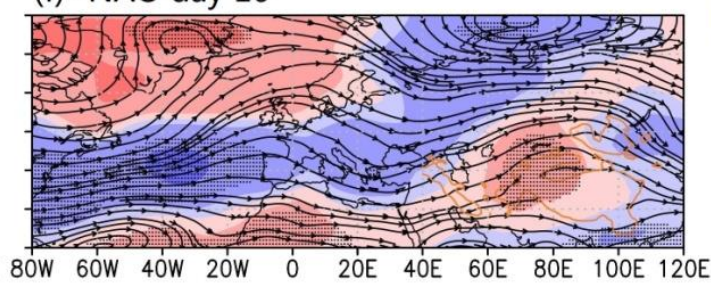

517 Fig. 6. The $500 \mathrm{hPa}$ geopotential height anomaly (in potential meters) and $700 \mathrm{hPa}$ wind stream line averaged on the peak day (day 0), day 5 and lag day 10, composited for 85 positive NAO events ( $a, b$ and $c$ ) and for 82 negative NAO events ( $d$, e and f). The brown lines represent the $1500 \mathrm{~m}$ isoheight. The dots represent the grid points where the $500 \mathrm{hPa}$ geopotential height anomaly were significant at the 95\% significance level. 
(a) +NAO WWD frequency anomaly and $700 \mathrm{hPa}$ moisture flux anomaly

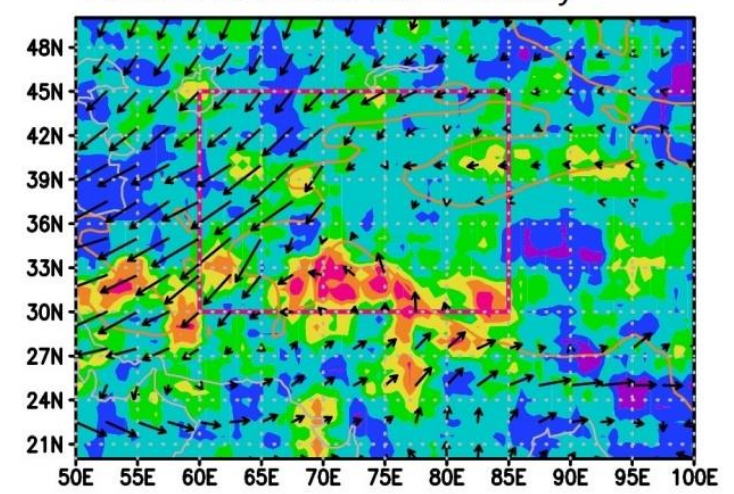

(b) -NAO WWD frequency anomaly and $700 \mathrm{hPa}$ moisture flux anomaly

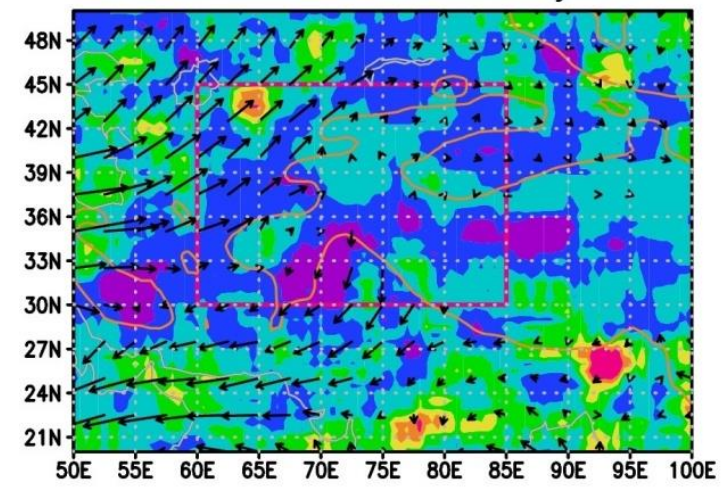
$\overrightarrow{0.5}$ (c) +NAO precipitation anomaly

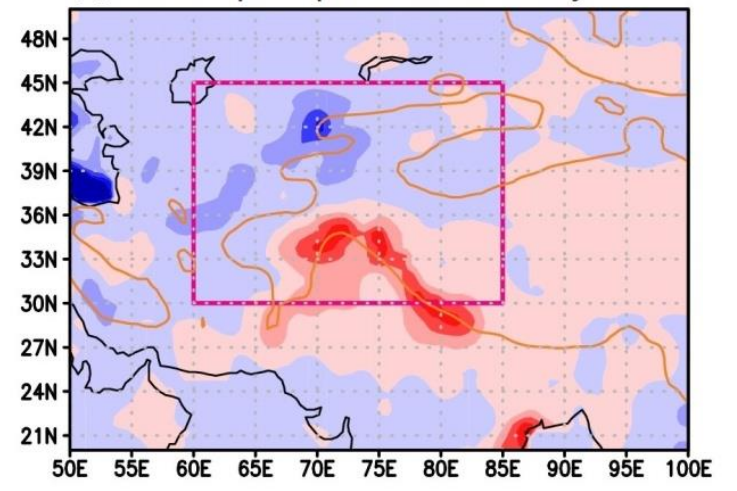

(d) -NAO precipitation anomaly

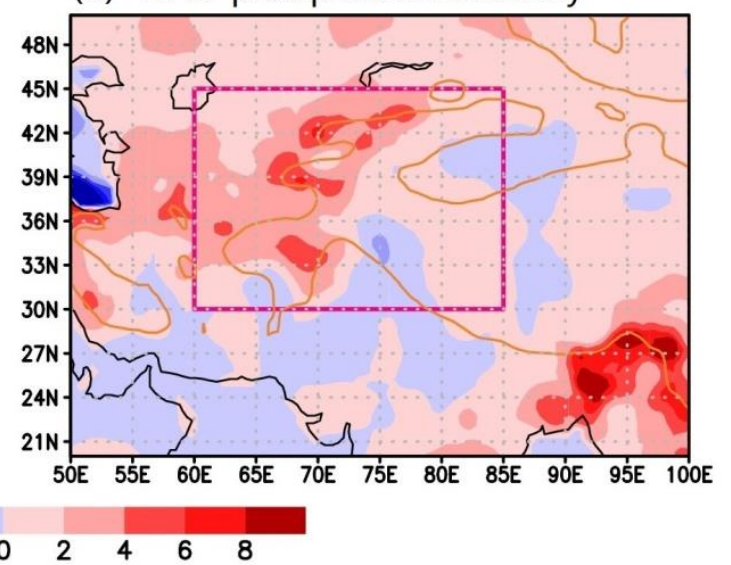

524 Fig. 7. The $700 \mathrm{hPa}$ moisture flux anomaly $\left(\mathrm{g} \mathrm{s}^{-1} \mathrm{hPa}^{-1} \mathrm{~cm}^{-1}\right.$, vectors) averaged from +5 day $(5$ days after the peak day) to the +10 day and WWD frequency anomaly (percentage per day, shaded), composited for 85 positive NAO events (a) and for 82 negative NAO events (b). Panels (c) and (d) are the same as panels (a) and (b), respectively, but for precipitation anomaly (in0.1 $\left.\mathrm{mm} \mathrm{d}^{-1}\right)$.The brown lines represent the $1500 \mathrm{~m}$ isoheight and the red boxes represent the 
(a) Positive NAO

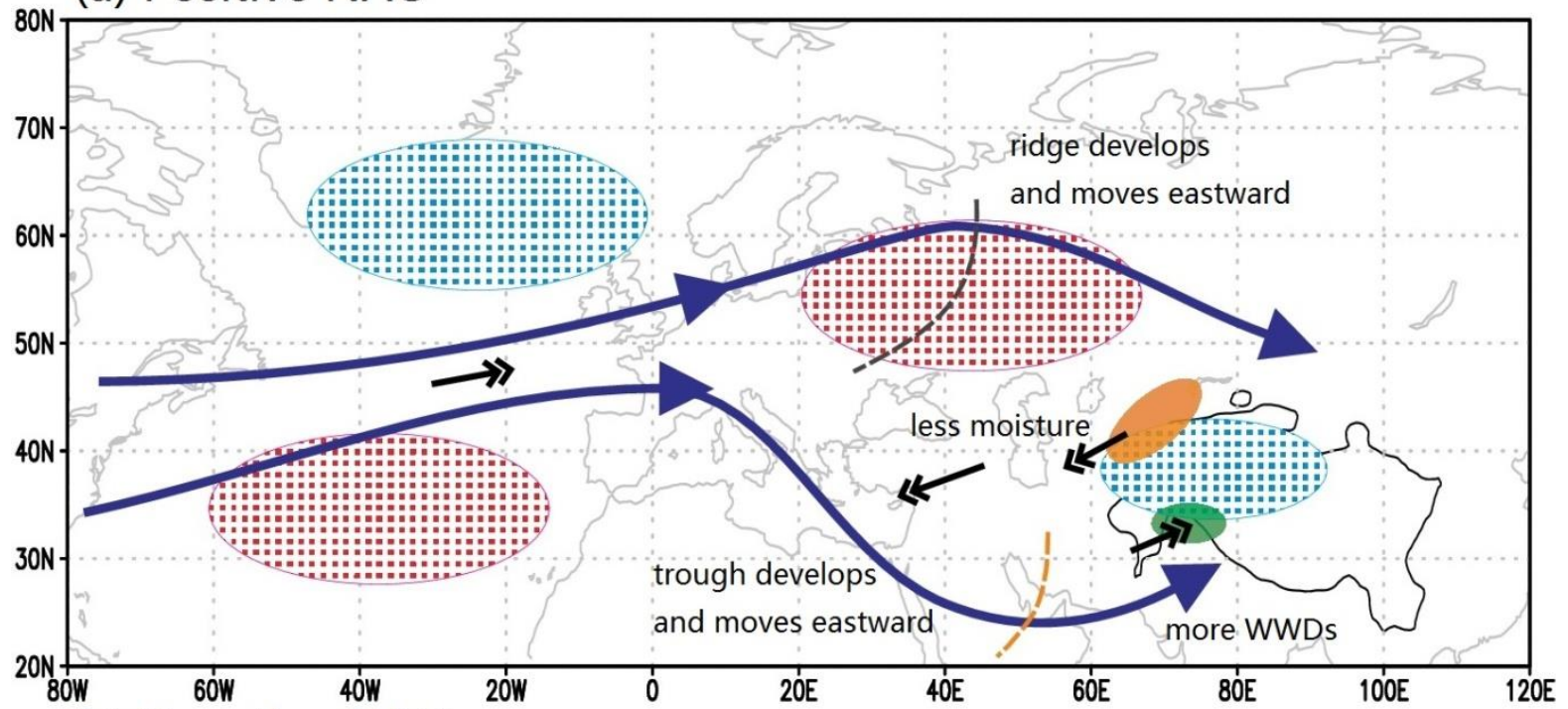

(b) Negative NAO

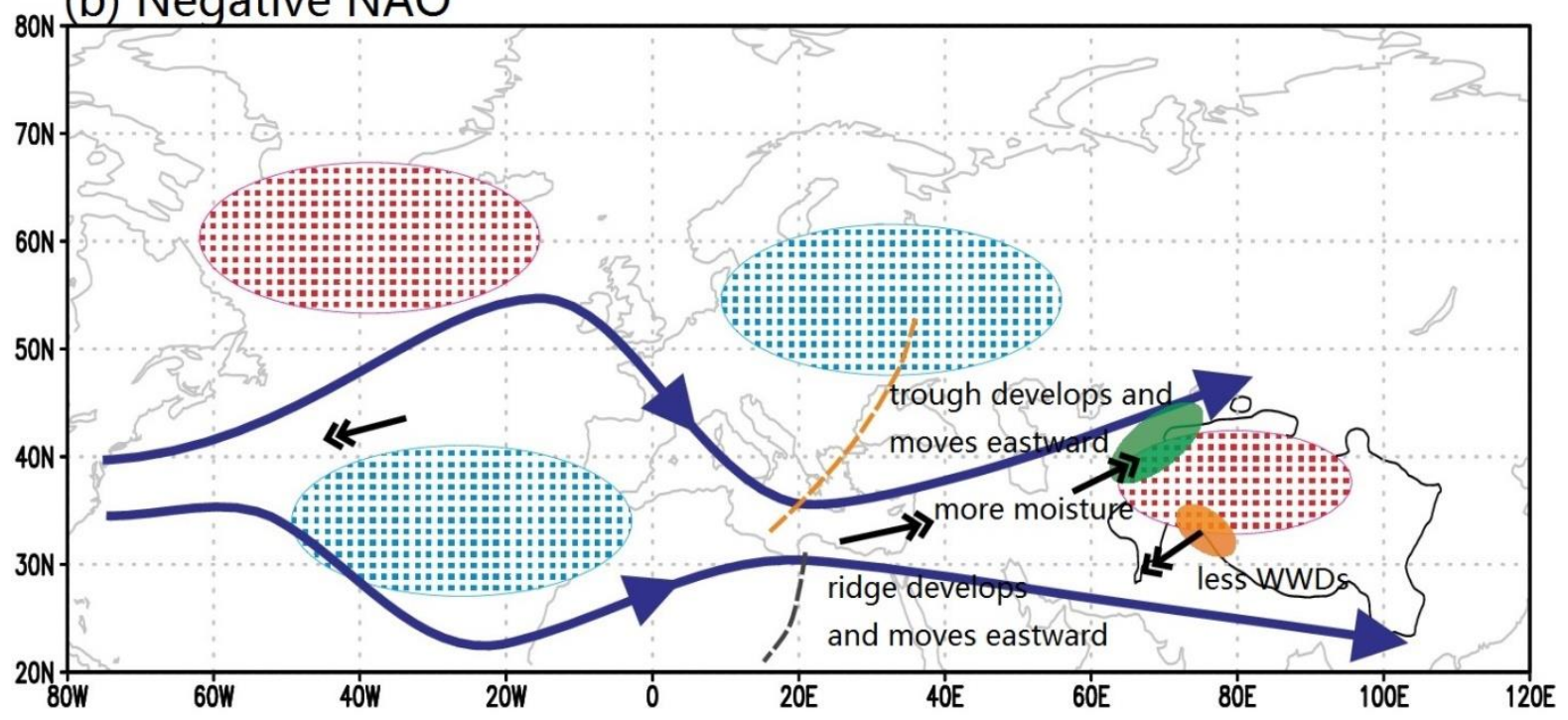

Fig. 8. Schematic diagrams showing how positive (a) and negative (b) NAO events influence

$\mathrm{hPa}$ positive and negative geopotential height anomalies. The blue lines represent the represent the $700 \mathrm{hPa}$ wind anomaly. The brown and gray dotted line represent troughs and 